\title{
The Comparison of Substantial and Dynamic Parameters Personal Value-Meaning Systems of American and Russian University Students
}

\author{
Nailia R. Salikhova ${ }^{1}$ \\ ${ }^{1}$ Kazan (Volga region) Federal University, Kazan, Russia \\ Correspondence: Nailia R. Salikhova, Kazan (Volga region) Federal University, Kremlyovskaya Street 18, Kazan, \\ 420008, Russia.
}

Received: December 29, 2014

Accepted: January 22, 2015 Online Published: February 11, 2015

doi:10.5539/res.v7n4p117

URL: http://dx.doi.org/10.5539/res.v7n4p117

\begin{abstract}
The comparison of substantial and dynamic parameters of personal value-meaning systems of American and Russian students $(\mathrm{n}=56)$ has revealed social and cultural differences among them. Substantial specifics demonstrate differences in the ranking of such values as freedom, health, cognition and close friendship within the general hierarchy of personal values. Dynamic specifics, in their turn, reveal themselves in a difference of perception of the attainability of values as well as in the level of realizability of the said values. The amount of the latter is significantly higher in American students. Results of this research search show that American students have defined their life goals through the process of education and fulfill the existential phase of realization of meaningfulness. Russian students, on the other hand, are still in the process of searching for meaning of activity and have yet to make their choice of life perspectives.
\end{abstract}

Keywords: personality, values, personal value-meaning systems, existential attitude, realizability of personal values

\section{Introduction}

\subsection{Relevance of the Subject}

Personality formation occurs in a process of appropriating the cultural values and historical experiences of a community to which a person belongs. Essential differences, therefore, between people belonging to different cultures, are brought to light through a system of personal values and meanings.

Values reflect experience of the social community's life activity. They are interiorized and integrated into the personality structure in the form of personal values.

In psychology, substantial sides of value- meaning regulation are mainly investigated: hierarchy of values and valuable orientations (Rokeach, 1973; Schwartz, 1994), structure and content of values (Cieciuch \& Schwartz, 2012; Cieciuch et al., 2014), the correlation of values with the meaning of life (Dezutter et al., 2014), mental states (Prokhorov, 2009), health and wellbeing (Brassai et al., 2011; Maercker et al., 2014). The dynamic sides of personality value functioning are investigated to a lesser degree. These are lines of personality's living space tension which arise upon the correlation of personality existential expectations and actual life situation, measures of value importance and perceived extent of its realization in life.

In cross-cultural research data has been accumulated on conceptual aspects of value-meaning systems, which are determined by a hierarchy of personal values. Representatives of these cultures focus mainly on either collectivism or individualism, which are often compared (Culture and psychology, 2001; Ohbuchi et al., 1999; Woldu \& Budhwar, 2011). Prime examples of countries where such is done are the USA and East Asia. Russia is often referred to a culture in which collectivist orientations prevail, however, in some aspects it is intermediate, bearing similarities to both western and eastern cultures.

Cross-cultural specifics of the conceptual aspect of personal value-meaning systems are usually studied separately from their dynamic aspect. The concept "dynamic" is used here in a sense which goes back to the idea of dynamic systems of forces and tension proposed in psychoanalysis. This paper discusses the tension that arises out of the conflict between value-saturated existential expectations and the perceived degree of realization of personal values in life. 
Operational indicators of such tensions bring out the discrepancy between the assessed importance of personal values and the perceived degree of realization of such values in actual life, as well as the interdependence of these evaluations.

\subsection{Problem Statement}

Research shows that a person estimates a value's degree of obtainability depending on the predominance of existential attitudes - it's realizability and unfeasibility (Salikhova, 2010).

The predominance of realizability is expressed as aspiration to reconcile a value's importance and its attainability. It is reached either as a result of external actions to implement the values in reality or due to internal, compensatory actions, such as defense mechanisms that lower the measure of value due to its unattainability. Respectively, people do what they can do in life, value what they have, and lower their assessment of the value of what is out of reach ("A bird in the hand is worth two in the bush"). Thus a person's attention is focused on searching for signs of realization of personal values in actual life situations. The "realizability index" (RI) - the positive correlation between the parameters of a value's importance and attainability - serves as its empirical indicator.

The predominance of unfeasibility directs a person's attention to the lack of signs of a personal value's realization in actual life and initiates their search outside the current life situation. It is expressed in the disparity or even polarization between the measures of importance and attainability of a value. They diverge from one another, with an increase of one parameter leading to the decline of another; what is attainable loses value while what is not attainable appears to have more value ("The grass is always greener on the other side", "We don't take care of what we have, but when we lose it, we cry"). In this case, the "bird in the bush" will be much more valuable than the "bird in hand" specifically because it has not been caught, and everything that is within the attainable zone loses value: it is impossible to estimate the value of the sand of the Sahara and the ice of Antarctica. The "difficulty index", the negative correlation between the parameters of a value's importance and attainability, and the "unfeasibility index", the direct correlative interconnection between a value's importance and the distance between its importance and attainability, serve as empirical indicators.

Earlier it was shown that the predominance of one of the above described existential attitudes is the internal condition for solving qualitatively different life problems that substantially correspond to the phases of man's existential interaction with the world, as described by Leontiev (2005). The predominance of a value's realizability corresponds to the phase of existential closedness, where a person realizes his acquired senses and values in life. The predominance of unfeasibility corresponds to the phase of existential openness to new conceptual horizons, when a person exhausts the meaning potential of former vital reference points and looks for or creates for himself new ones. Existential attitudes of realizability and unfeasibility of personal values complement each other and regularly alternate in a person's development (Salikhova, 2010).

These dynamic characteristics of personal value-meaning systems have been studied in sufficient detail in Russia however were not analyzed from the point of cross-cultural comparisons. Not clear also, is the socio-cultural specifics of the hierarchy of values accompanied by differences in the dynamic aspects of personal value-meaning systems, in particular, by the predominance of realizability or unfeasibility of personal values.

\subsection{Objective of the Research}

The goal of this research is to raise this question and to reveal socio-cultural specifics of conceptual and dynamic aspects of personal value meaning systems of Russian and American students.

\section{Methods}

\subsection{Data collection Methods}

In order to collect empirical data the M. Rokeach (1973) technique as modified by E.B. Fantalova (2001) was used. In pairs students compared twelve terminal values by criteria of their importance and attainability. The list included the following values: active life, health (both physical and mental), interesting job, the beauty of nature and art, love (both sensual and spiritual closeness to a partner), wealth (absence of financial constraints), close friendship, self-confidence (absence of inner conflicts and doubts), cognition (including ability to extend knowledge and get new experience), freedom (independence of mind and action), happy family life, creativity. Each group of students was given the list of values in their native languages.

The following criteria were defined in each group: 1) importance of each of the values; 2) attainability rate; 3) personal realizability index of the values calculated as correlation between a value's importance and attainability for each student (Pearson's r); 4) mean value of individual indexes in each sample; 5) realizability (correlation 
between importance and attainability) and unfeasibility (correlation between parameters of importance and the difference between its importance and attainability) indexes of each value according to group data.

\subsection{Description of the Survey Sample}

The participants consisted of 56 senior students: 28 students of Columbia University (New York, USA) and 28 students of Kazan State University (Kazan, Russia). The age of the participants was between 21 and 23 years, and the mean age was 21.74 years.

\subsection{Methods of Data Processing}

The data were processed applying the descriptive statistics procedures, independent two-sample Student t-test, correlation analysis based on the Pearson's formula.

\section{Results}

\subsection{Results of the Comparison of the Importance of Values for Russian and American Students}

The distribution of all measured variables in the sample was close to normal; it allowed to apply the correlation analysis using Pearson's formula.

The comparative analysis of hierarchy of values of the Russian and American students are presented in the table 1.

Table 1. The comparison of the importance of values for Russian and American students

\begin{tabular}{llll}
\hline Values & American students $\overline{\mathrm{a}}(\sigma)$ & Russian students $\overline{\mathrm{a}}(\sigma)$ & Student's t-test \\
\hline Active life & $8.0(2.7)$ & $9.0(2.2)$ & -1.3 \\
Health & $6.6(2.9)$ & $8.3(2.7)$ & $-2.0^{*}$ \\
Interesting job & $4.3(1.6)$ & $5.1(2.1)$ & -1.4 \\
The beauty of nature and art & $1.7(2.0)$ & $1.2(1.8)$ & 0.6 \\
Love & $7.6(2.5)$ & $7.4(2.3)$ & 0.1 \\
Wealth & $8.8(2.4)$ & $8.0(1.8)$ & 1.3 \\
Close friendship & $3.2(2.3)$ & $5.9(2.7)$ & $-3.6^{* * *}$ \\
Self-confidence & $4.7(2.3)$ & $5.0(2.1)$ & -0.3 \\
Cognition & $5.0(2.2)$ & $1.9(1.6)$ & $5.6^{* * *}$ \\
Freedom & $7.7(2.6)$ & $4.6(2.0)$ & $4.6^{* * *}$ \\
Happy family life & $6.4(2.4)$ & $7.1(2.5)$ & -0.8 \\
Creativity & $2.0(2.3)$ & $2.6(2.3)$ & -0.8 \\
\hline
\end{tabular}

Legend: $\overline{\mathrm{a}}$ - average, $\sigma$ - dispersion; asterisks indicate statistically significant values at the level $\mathrm{p}<0.05\left(^{*}\right)$, $\mathrm{p}<0.001(* * *)$.

\subsection{Results of the Comparison of Attainability Values in the Samples of Russian and American Students}

The comparative analysis of value's attainability estimate of the Russian and American students are presented in the table 2 .

Table 2. The comparison of attainability values in the samples of Russian and American students

\begin{tabular}{llll}
\hline Values & American students $\overline{\mathrm{a}}(\sigma)$ & Russian students $\overline{\mathrm{a}}(\sigma)$ & Student's t-test \\
\hline Active life & $8.9(2.7)$ & $8.7(2.2)$ & 0.1 \\
Health & $4.7(1.8)$ & $5.5(1.7)$ & -1.6 \\
Interesting job & $6.1(1.9)$ & $4.8(2.5)$ & $2.0^{*}$ \\
The beauty of nature and art & $3.9(3.2)$ & $5.4(2.2)$ & -1.8 \\
Love & $6.9(3.0)$ & $7.4(2.3)$ & -0.6
\end{tabular}




$\begin{array}{llll}\text { Wealth } & 2.9(2.3) & 2.7(2.0) & 0.2 \\ \text { Close friendship } & 4.6(2.7) & 8.0(2.5) & -4.5^{* * *} \\ \text { Self-confidence } & 5.6(2.4) & 6.1(2.0) & -0.7 \\ \text { Cognition } & 8.5(2.1) & 9.3(2.5) & -1.2 \\ \text { Freedom } & 8.6(2.0) & 3.9(1.9) & 8.3^{* * *} \\ \text { Happy family life } & 2.5(3.0) & 2.0(3.1) & 0.5 \\ \text { Creativity } & 2.9(2.7) & 2.1(2.4) & 1.0\end{array}$

Legend: $\bar{a}$ - average, $\sigma$ - dispersion; asterisks indicate statistically significant values at the level $\mathrm{p}<0.05(*)$, $\mathrm{p}<0.001(* * *)$.

\subsection{Results of the Comparison of Individual Realizability Indexes of Russian and American Students}

Comparing the individual realizability indexes are presented in the table 3.

Table 3. The comparison of individual realizability indexes (RI) in groups of American and Russian students

\begin{tabular}{|c|c|c|c|c|}
\hline Parameters & $\overline{\mathrm{a}}(\sigma)$ & Student's t-test & t-crit. & Statistical significant level \\
\hline American students $(\mathrm{n}=23)$ & $0.37(0,18)$ & 3.0 & 2.56 & $\mathrm{p}<0.01$ \\
\hline Russian students $(n=23)$ & $0.07(0,42)$ & & $(p<0.01)$ & \\
\hline
\end{tabular}

3.4 Results of the Comparison of Values Realizability (RI) and Unfeasibility (UI) Indexes among American and Russian Students

Comparing values realizability (RI) and unfeasibility (UI) indexes among American and Russian students are presented in the table 4 .

Table 4. The comparison of values realizability (RI) and unfeasibility (UI) indexes among American and Russian students

\begin{tabular}{lllll}
\hline Values & \multicolumn{2}{l}{ American students } & \multicolumn{2}{l}{ Russian students } \\
& RI & UI & RI & UI \\
\hline Active life & $0.74^{* * *}$ & 0.37 & 0.16 & $0.64^{* * *}$ \\
Health & $0.45^{*}$ & $0.79^{* * *}$ & 0.06 & $0.84^{* * *}$ \\
Interesting job & $0.53^{* *}$ & 0.34 & 0.27 & $0.39^{*}$ \\
The beauty of nature and art & $0.44^{*}$ & 0.22 & $0.60^{* *}$ & 0.04 \\
Love & $0.68^{* * *}$ & 0.29 & -0.05 & $0.72^{* * *}$ \\
Wealth & 0.19 & $0.65^{* * *}$ & -0.13 & $0.73^{* * *}$ \\
Close friendship & $0.75^{* * *}$ & 0.16 & $0.57^{* *}$ & $0.45^{*}$ \\
Self-confidence & $0.74^{* * *}$ & 0.29 & 0.29 & $0.60^{* *}$ \\
Cognition & $0.49^{*}$ & $0.52^{* *}$ & -0.20 & $0.65^{* * *}$ \\
Freedom & 0.16 & $0.74^{* * *}$ & 0.08 & $0.70^{* * *}$ \\
Happy family life & 0.03 & $0.74^{* * *}$ & 0.37 & $0.41^{*}$ \\
Creativity & $0.60^{* *}$ & 0.30 & 0.06 & $0.67^{* * *}$ \\
\hline
\end{tabular}

Asterisks indicate the values of reached statistical significance at the p-level $\mathrm{p}<0.05\left(^{*}\right), \mathrm{p}<0.01\left(^{* *}\right), \mathrm{p}<0.001$ $(* * *)$ 


\section{Discussions}

\subsection{Discussion of the Comparison of the Importance of Values for Russian and American Students}

The comparative analysis of hierarchy of values (see table 1) of the Russian and American students revealed points common to all students with a number of differences. Both groups mentioned active life, wealth and love as high-ranking values, whereas creativity and the beauty of nature and art were low-ranking values. Self-confidence was ranked eighth in both groups. The greatest difference in the values assessment, apparently due to cultural differences, was the ranking of freedom, health, cognition and close friendship. Freedom was more important to the American students (ranked three compared to a ranking of nine in the Russian group). Close friendship was more important to the Russian students (ranked three versus a rank of eight among the American students). Cognition was higher for the American students (ranked seven compared to eleven).

\subsection{Discussion of the Comparison of Attainability Values in the Samples of Russian and American Students}

Comparing each value's attainability estimate (table 2) demonstrated that an active life and cognition appeared to be considered most attainable in both groups. The most unattainable, with small variations, were wealth, creativity and a happy family life. The most significant differences were revealed in the attainability of freedom, an interesting job and close friendship.

The attainability of freedom and an interesting job was higher among the American students, whereas close friendship was evaluated as more attainable by the Russian students.

The difference in the importance and attainability of close friendship is derived from traditional Russian communal values. Close friendship is valued more highly by the Russians. The American students, on the other hand, demonstrated a higher interest in self-oriented values, such as an interesting job and cognition. This is typical of North American culture. At the same time, similarities between the importance and attainability of several values could be explained by the fact that both groups of students belong to the same social and age group.

\subsection{Discussion of the Comparison of Individual Realizability Indexes of Russian and American Students}

Comparing the individual realizability indexes demonstrated that they are much higher (at the level $\mathrm{p}<0.01$ ) among American students compared with Russians (table 3). American students value highly what they already possess, approaching the values more realistically. At the same time they decrease the value of unattainable items. Russian students, on the other hand, estimate inaccessible values as more important ("two birds in the bush is worth more than one in the hand" principle).

\subsection{Discussion of the Comparison of Values Realizability (RI) and Unfeasibility (UI) Indexes among American and Russian Students}

Similar distinctions are revealed when realizability and unfeasibility indexes at certain life areas are compared (table 4). The majority of the American students (58\%, or 7 of 12) assessed the importance of a value as directly connected to its attainability. The Russian students assessed only two values this way. At the same time, for the majority of values $(75 \%$, or 9 of 12$)$ in this sample dependence exists among levels of value's importance and difference between its importance and attainability. In other words, the unfeasibility index is greatly expressed. The most opposing values in this respect were an active life, self-confidence, and creativity. Love, health and cognition demonstrated a slightly less expressed difference of the same origin.

All the foregoing leads us to the conclusion that the American students implement their potentiality of initiative at the degree allowing them to fulfill their capabilities within the limits of their own reality of meaning. These students will fulfill their capability of professional growth at a better and fuller degree while studying at university. The Russian students, in their turn, seem to be fulfilling their potentiality of initiative at a lesser degree. They are, therefore, in the process of an inner search for meaning, striving for the ability and readiness to make new life decisions. This might lead to re-making a choice within the limits of their current sphere, e.g. in the form of changing their college, university or major. Moreover, this might also lead to a complete change of other spheres of their lives, and even to the temporary banning of any activity directed at developing their professional and personal skills and experience. These students will be less task-oriented and effective at fulfilling the potential of their professional growth as provided by education and training process.

The above described situation could be said to be a result of rapid social and economic changes taking place in Russia. Students make their choice of career under a greater pressure of uncertainty. The profession they choose is not necessarily connected to their future employment. At the same time in Russia there is significantly less possibility of constructing one's own educational strategy aimed at reaching a definite work place than in the 
USA. Due to this fact Russian students tend to be uncertain about their aims even after they have chosen their alma mater and throughout their education period. This uncertainty is reflected in the peculiarities of dynamic aspects of personal value-meaning systems.

\section{Conclusions}

This research has revealed similarities, as well as differences, of substantial and dynamic parameters of personal value-meaning systems of American and Russian students. Similarities could be explained by the fact that participants from both groups, all being students, belonged to the same social and age groups, whereas differences could be derived from the individualistic trend in American culture on the one hand, and the prevailing collectivist orientation of the Russian culture on the other hand. Differences in the dynamic parameters witness to the fact that American students have already defined their life goals and are in the process of their fulfillment, whereas Russian students are still searching for meaningful life perspectives.

\section{Acknowledgments}

The work is performed according to the Russian Government Program of Competitive Growth of Kazan Federal University

\section{References}

Brassai, L., Piko, B. F., \& Steger, M. F. (2011). Meaning in life: Is it a protective factor for adolescents' psychological health? International Journal of Behavioral Medicine, 18(1), 44-51. http://dx.doi.org/10.1007/s12529-010-9089-6

Cieciuch, J., \& Schwartz, S. H. (2012). The number of distinct basic values and their structure assessed by PVQ-40. Journal of Personality Assessment, 94(3), 321-328. http://dx.doi.org/10.1080/00223891.2012.655817

Cieciuch, J., Davidov, E., Vecchione, M., \& Schwartz, S. H. (2014). A hierarchical structure of basic human values in a third-order confirmatory factor analysis. Swiss Journal of Psychology, 73(3), 177-182. http://dx.doi.org/10.1024/1421-0185/a000134

Dezutter, J., Waterman, A. S., Schwartz, K., Luyckx, S. J., Beyers, W., Meca, A., ... \& Caraway, S. J. (2014). Meaning in life in emerging adulthood: A person-oriented approach. Journal of Personality, 82(1), 57-68. http://dx.doi.org/10.1111/jopy.12033

Fantalova, E. B. (2001). Diagnostics and psychotherapy of inner conflict. Samara: BAHRAH.

Leontiev, D. A. (2005). New horizons in the problem of meaning in psychology. In The problem of meaning in the humanities (to the $110^{\text {th }}$ anniversary of Victor Frankl's birth) (pp. 36-48). Moscow: Smysl.

Maercker, A., Zhang, X. C., Gao, Z., Kochetkov, Y., Lu, S., Sang, Z., ... Margraf, J. (2014). Personal value orientations as mediated predictors of mental health: A three-culture study of Chinese, Russian, and German university students. International Journal of Clinical and Health Psychology (Article in press).

Matsumoto, D. (2001). Culture and psychology. Oxford: University Press.

Ohbuchi, K., Fukushima, O., \& Tedeschi, J. T. (1999). Cultural values in conflict management: Goal orientation, goal attainment, and tactical decision. Journal of Cross-cultural Psychology, 30, 51-71. http://dx.doi.org/10.1177/0022022199030001003

Prokhorov, A. O. (2009). Notional regulation of mental states. Psikhologicheskii Zhurnal, 30(2), 5-17.

Rokeach, M. (1973). The Nature of Human Values. New York: Free Press.

Salikhova, N. R. (2010). Value-sense organization of a person's life-space. Kazan: Kazan University Press.

Schwartz, H. S. (1994). Are There Universal Aspects in the Structure and Contents of Human Values? Journal of Social Issues, 50(4), 19-45. http://dx.doi.org/10.1111/j.1540-4560.1994.tb01196.x

Woldu, H., \& Budhwar, P. S. (2011). Cultural value orientations of the former communist countries. $A$ gender-based analysis, 22(7), 1365-1386. 


\section{Copyrights}

Copyright for this article is retained by the author(s), with first publication rights granted to the journal. This is an open-access article distributed under the terms and conditions of the Creative Commons Attribution license (http://creativecommons.org/licenses/by/3.0/). 